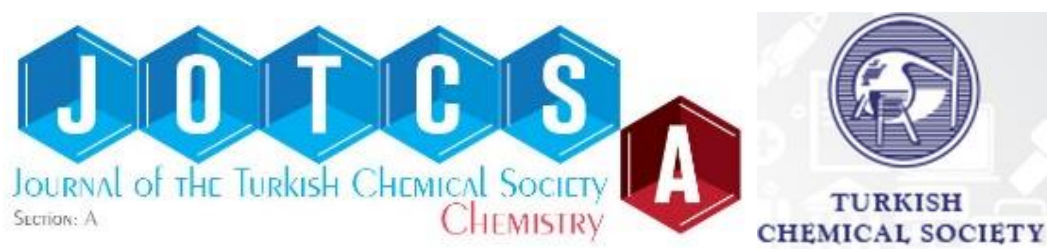

\title{
Electrochemistry and sensitive determination of a metal complex azo dye using graphite paste electrode modified with $\mathrm{Na-bentonite}$
}

\author{
Sinem Ortaboy ${ }^{1}$ \\ ${ }^{1}$ Chemistry Department of Engineering Faculty, Istanbul University, 34720, Istanbul, Turkey
}

\begin{abstract}
Graphite and its composites have gained considerable attention in electrochemical applications due to their excellent structural, electrical, and chemical properties. In this study, a graphite paste electrode (GPE) modified with natural Na-bentonite (BGPE) is fabricated and utilized for the sensitive determination of Lanaset Red G (LRG) which is a kind of azo containing metal complex dye. The BGPE shows excellent enhancement in peak currents as compared to that of the GPE. The detection limit of LRG is determined to be as low as $0.65 \pm 0.08 \mathrm{nM}$ when utilizing the BGPE as the working electrode in square wave voltammetry experiments (SWV). The electrochemical behavior of LRG is also investigated using a cyclic voltammetry (CV) technique to propose reaction mechanisms. Effects of $\mathrm{pH}$ and scan rate on the electrochemical behavior of LRG are studied to calculate transfer coefficients, the number of protons and electrons transferred in the redox reaction. The results show that a quasireversible reaction occurs on the BGPE surface/electrolyte interface. The morphology and the chemical characterization of both BGPE and GPE electrodes are investigated by the atomic force microscopy (AFM) technique and the diffuse reflectance infrared Fourier transform spectroscopy (DRIFT), respectively.
\end{abstract}

Keywords: Voltammetry, sensitive determination, graphite, bentonite, azo dye.

Submitted: August 17, 2017. Accepted: September 11, 2017.

Cite this: Ortaboy S. Electrochemistry and sensitive determination of a metal complex azo dye using graphite paste electrode modified with Na-bentonite. JOTCSA. 2017;4(3):931-52.

DOI: $10.18596 /$ jotcsa.334999.

*Corresponding author. E-mail: ortaboy@istanbul.edu.tr. 


\section{INTRODUCTION}

Industrial wastewater is one of the serious problems which negatively affect the ecosystem of living organisms in the natural environment (1). In particular, dye-contaminated wastewater is the major sources of the water pollution due to the easy penetration to the large water reservoirs, underground water sources, rivers, lakes, and shorelines (2). Among a wide variety of industries, textile plants generate a large amount of wastewater containing reactive dyes, surfactants, organic and inorganic toxic substances during dyeing and finishing processes (3, 4). Thus, before all these hazardous substances are discharged to the environment, the sensitive determination and accurate quantification are of vital importance to estimate their harmful effects on biological systems. In particular, dyes which contain heavy metal ions should be determined carefully before discharging to the environment because even their trace amounts cause serious health problem for humans, animals, and creatures of aquatic life (5).

Lanaset Red G (LRG) is a metal complex azo dye that extensively used for dyeing various textile fibers such as wool, silk, and polyamide due to their unique properties such as high wet- and light- fastness, brightness in color and higher stability (6). It is well known that acid dyes are resistant to biological degradation in the soil due to their negatively charged chromophore groups (7). Thus, their long-term accumulations in the natural water sources can cause undesirable effects on soil compositions and water quality.

Recently, great attention has been paid to the sensitive determination of dye-containing effluents in various environmental matrices. Electroanalytic, chromatographic, spectrometric, and colorimetric methods are the most utilized methods for sensitive detection of dyes in environmental pollutants. Among them, electrochemical techniques gain importance due to its unique features such as easy process, low cost, short response time, high sensitivity, and selectivity (7-10). In addition, the sensitivity of this method can be effectively increased using various composite materials as the sensing agents. Current researches focus on the development of new alternative composite materials for enhanced electrochemical performance. In this regard, carbon-based materials have a growing interest because their excellent chemical stability, high electrical conductivity, and chemical inertness make them attractive components of composite materials. On the other hand, it is desirable to use porous materials to obtain high surface area which provides more sites for sensing of the analyte. In this regard, earth-abundant clay materials are good options to consider due to their excellent surface area and low cost (11).

Bentonite is a kind of natural clay whose major constituent is montmorillonite. This mineral clay is identified by three-layered aluminosilicates that consist of one octahedral alumina layer sandwiched between two tetrahedral silica layers, as shown in Figure 1. Some of the most important advantages of montmorillonite are that they have an excellent swelling capacity 
Ortaboy, JOTCSA. 2017; 4(3): 931-952.

(12), large surface area, good ion-exchange properties, environmental-friendly nature, low cost and effective charge diffusion behavior $(13,14)$.

In this study, both the electrochemical behavior and the sensitive determination of LRG are investigated using graphite paste composite electrode which is modified with the natural Nabentonite. Cyclic voltammetry experiments are performed to estimate possible reaction mechanisms while square wave voltammetry experiments are performed to calculate the detection limit of LRG. The morphological structure and the chemical analysis of the BGPE are investigated utilizing AFM and DRIFT spectroscopy techniques. The results revealed that the modification of bentonite with graphite paste electrode provides significant improvements in the electrochemical activity and enables the sensitive determination of LRG up to the concentration of $6.5 \times 10^{-10} \mathrm{M}$. The enhanced performance is attributed to the excellent surface properties of BGPE.

\section{MATERIALS AND METHODS}

\section{Reagents and solutions}

All chemicals are of analytical grade and they are used as received without further purification. Sodium dihydrogen phosphate $\left(\mathrm{NaH}_{2} \mathrm{PO}_{4}\right)$, disodium hydrogen phosphate $\left(\mathrm{Na}_{2} \mathrm{HPO}_{4}\right)$, sodium hydroxide $(\mathrm{NaOH})$, hydrochloric acid $(\mathrm{HCl})$, sodium tetraborate $\left(\mathrm{Na}_{2} \mathrm{~B}_{4} \mathrm{O}_{7}\right)$, acetic acid $\left(\mathrm{CH}_{3} \mathrm{COOH}\right)$, sodium acetate $\left(\mathrm{CH}_{3} \mathrm{COONa}\right)$, ethanol $(\mathrm{EtOH})$, and acetone are purchased from Merck Chemical Company (Darmstadt, Germany). The Lanaset Reg G dye is supplied from Setaş Chemistry Cooperation in Bursa, Turkey. The paraffin oil and the graphite powder ( $\sim 100$ $\mu \mathrm{m})$ are purchased from Sigma-Aldrich. Bentonite clay is obtained from Samaş Industrial Minerals Inc. (Reşadiye in Tokat, Turkey). Aqueous solutions used in this study are freshly prepared with ultrapure water $(\geq 18 \mathrm{M} \Omega \mathrm{cm}$ ) generated by a Millipore Direct-Q3 water system (Merck KGaA, Darmstadt, Germany).

Stock solutions of the LRG $(0.1 \mathrm{M})$ are prepared daily by dissolving appropriate amounts of water using volumetric flasks. Phosphate (PBS), acetate (ABS), and borate buffer (BBS) solutions with different $\mathrm{pH}$ levels are adjusted mixing different volumes of $0.05 \mathrm{M} \mathrm{Na}_{2} \mathrm{HPO}_{4}$ $\mathrm{NaH}_{2} \mathrm{PO}_{4}, 0.05 \mathrm{M} \mathrm{CH} 3 \mathrm{COOH}-\mathrm{CH}_{3} \mathrm{COONa}$ and $0.05 \mathrm{M} \mathrm{Na}_{2} \mathrm{~B}_{4} \mathrm{O}_{7}-\mathrm{NaOH}$ solutions, respectively.

\section{Apparatus}

All voltammetric experiments are carried out with Gamry Instruments Reference 600 Potentiostat/Galvanostat ZRA system (Gamry Instruments, Inc., Warminster, PA, USA) coupled with a conventional three electrode system. The paste electrode (GPE, $5.0 \mathrm{~mm}$ diameter) and the bentonite-modified graphite paste electrode (BGPE) is used as the working electrodes (WEs), the saturated $\mathrm{Ag} / \mathrm{AgCl}(\mathrm{KCl})$ as the reference electrode $(\mathrm{RE})$ and a platinum 
Ortaboy, JOTCSA. 2017; 4(3): 931-952.

RESEARCH ARTICLE

wire as the counter electrode (CE). All data are recorded with the Echem Analyst Potentiostat/Galvanostat software interfaced with a computer.

The morphological structure of the working electrode surfaces is examined in air under ambient condition using Ambient AFM (Nanomagnetics Instruments, UK) which is operated in the dynamic mode. Samples are scanned with $5 \mu \mathrm{ms}^{-1}$ scanning rate and $256 \times 256$ pixels resolution to obtain a view of $3 \times 4 \mu \mathrm{m}^{2}$ area using aluminum-coated silicon cantilevers. PPPNCHR type AFM tips with the resonance frequency of $330 \mathrm{kHz}$ and the force constant of $42 \mathrm{Nm}^{-}$ 1 (Nanosensors, Switzerland) are used for tapping-mode AFM measurements. Statistical parameters are calculated from AFM images using NMI Viewer 2.0.2 Image Analyzer Software. For the sample preparation, stainless steel sample holders are used and the electrical contact between sample surface and the holders is provided using conductive silver paste (PELCO ${ }^{\circledR}$ Colloidal Silver).

The diffuse reflectance infrared Fourier-transform (DRIFT) spectroscopy is conducted with a Bruker Alpha-T DRIFT spectrometer with a 528/D model diffuse reflection unit containing two sample cups ( $3 \mathrm{~mm}$ deep, $6 \mathrm{~mm}$ in diameter). Powdery samples are mixed with oven-dried, spectroscopic-grade $\mathrm{KBr}$ (refractive index of 1.559) using an agate mortar and pestle. The concentration of the samples in the $\mathrm{KBr}$ is kept constant at $2 \%(\mathrm{w} / \mathrm{w})$. All spectra are recorded by averaging 100 scans at a resolution of $4 \mathrm{~cm}^{-1}$ and data acquisition are performed using OPUS 6.5 software (Bruker Optics Inc.).

A Jenway Ion Analyzer pH-meter (Model 3040) with a combined glass electrode is used to measure $\mathrm{pH}$ of the buffer solutions, which are used as the supporting electrolyte in voltammetric experiments.

The 3D chemical structure of the LRG is designed by "Avogadro" molecular modeling software program with Open Babel version of 2.3.2.

All electrochemical experiments are performed at room temperature $\left(25 \pm 2^{\circ} \mathrm{C}\right)$.

\section{Fabrication of the working electrodes}

The BGPE is prepared with the mixture of $0.6 \pm 0.05 \mathrm{~g}$ of bentonite, $1.0 \pm 0.05 \mathrm{~g}$ of graphite powder and $\sim 0.20 \mathrm{~cm}^{3}$ of paraffin oil by homogenizing manually in a mortar using a pestle. The appropriate amount of paraffin oil is determined by analyzing the electrochemical response of $0.1 \mathrm{mM}$ LRG in pH 5 ABS electrolyte. The results show that the higher amounts of paraffin negatively affect the electrochemical performance while its lower amounts are not enough to bind the composite mixture. The appropriate ratio of bentonite/graphite is calculated using square wave voltammetry (SWV). A series of bentonite in different mass is added to the $0.5 \mathrm{~g}$ graphite, then the electrochemical responses of as prepared bentonite/graphite composites are 
Ortaboy, JOTCSA. 2017; 4(3): 931-952.

RESEARCH ARTICLE

analyzed to obtain the optimum ratio. The results are shown in Table 1 . Since the maximum peak current is observed for the composite ratio of 0.6 , all electrochemical experiments are performed using this mixture. The bare GPE is prepared with the same procedure without using bentonite. As-prepared graphite pastes are poured and pressed into the cavity of the polypropylene electrode body of insulin syringes which has the barrel diameter of $0.5 \mathrm{~cm}$. A piece of weighing paper is used for polishing in order to obtain smooth and shiny electrode surface. The height of the graphite paste mixture in the column is kept constant within $0.5 \pm 0.06 \mathrm{~cm}$. Before starting the voltammetric experiments, the working electrode is standardized with an open circuit potential in the appropriate buffer solution until the current values are constant. The electrical contact of the electrodes is established with a Cu wire in the diameter of $0.5 \mathrm{~mm}$.

Table 1: CV responses of $0.1 \mathrm{mM}$ LRG on different BGPE surfaces which are prepared changing the amounts of bentonite. The results are obtained in ABS electrolyte with $\mathrm{pH} 5$ and the scan rate is selected as $75 \mathrm{mAcm}^{-2}$.

\begin{tabular}{|c|c|c|c|c|c|c|}
\hline \multicolumn{7}{|l|}{ Bentonite/Graphite } \\
\hline $\begin{array}{l}\text { composite ratio } \\
(w / w)\end{array}$ & 0.1 & 0.2 & 0.4 & 0.6 & 0.8 & 1.0 \\
\hline $\begin{array}{l}\text { Anodic current } \\
\text { density }\left(\mu \mathrm{Acm}^{-2}\right)\end{array}$ & 12.4 & 27.7 & 55.9 & 116.1 & 109.8 & 98.2 \\
\hline
\end{tabular}

\section{Procedure}

The following steps are performed for each voltammetric experiment. First, the working electrode is immersed in the voltammetric cell containing $10 \mathrm{~cm}^{3}$ of supporting electrolyte with the desired $\mathrm{pH}$. Electrodes are standardized at the scan rate of $0.10 \mathrm{Vs}^{-1}$ in the $0-1.2 \mathrm{~V}$ potential window utilizing cyclic voltammetry (CV) in blank buffer solutions. The WE is taken out from the cell, rinsed with water to remove residual salt, and immersed in another electrochemical cell containing $10 \mathrm{~cm}^{3}$ of LRG solution in the supporting electrolyte. The CVs are investigated for different $\mathrm{pH}$ levels and scan rates while square wave voltammetry (SWV) are evaluated for different concentration of LRG dye. Acetate, phosphate, and borate buffers are used as supporting electrolytes to investigate the effect of $\mathrm{pH}$ on the voltammetric responses of LRG in the $\mathrm{pH}$ range of 4-5.5, 6.0-7.5 and 8.5-10, respectively. When necessary, the surface of the paste is refreshed by refilling the electrode with the new paste since the electrochemical sensitivity of the electrode decreases after a series of electrochemical measurements. The trace level determination of the LRG is performed in $5.0 \mathrm{nM}-1.6 \mu \mathrm{M}$ concentration range.

\section{RESULTS AND DISCUSSION}


Ortaboy, JOTCSA. 2017; 4(3): 931-952.

\section{Structural and Chemical Characterization}

The chemical composition of the natural Na-bentonite used as the modifying agent in this study is represented in Table 2. It is worth to note that Na-bentonite mainly composed of $61.28 \% \mathrm{SiO}_{2}$ and $17.79 \% \mathrm{Al}_{2} \mathrm{O}_{3}$ components (15).

Table 2: Chemical characteristics of natural Na-bentonite (15).

\begin{tabular}{ccccccc}
\hline $\mathrm{SiO}_{2}$ & $\mathrm{Al}_{2} \mathrm{O}_{3}$ & $\mathrm{Fe}_{2} \mathrm{O}_{3}$ & $\mathrm{CaO}$ & $\mathrm{Na}_{2} \mathrm{O}$ & $\mathrm{MgO}$ & $\mathrm{K}_{2} \mathrm{O}$ \\
\hline 61.3 & 17.8 & 3.0 & 4.5 & 2.7 & 2.1 & 1.4 \\
\hline
\end{tabular}

Fabrication steps of the BGPE, as explained in detail above, are illustrated in Figure 1 . In this figure, the three-layered structure of montmorillonite, which is the major component of bentonite, is represented in the blue circle.

Scheme 1 shows the molecular structures of the LRG designed by both 3D and 2D molecular modeling software package programs.

The chemical characterization of the electrodes is performed using diffuse reflectance Fourier transform spectroscopy (DRIFT) while the morphological structure is clarified using the atomic force microscopy (AFM) technique as discussed in detail below.

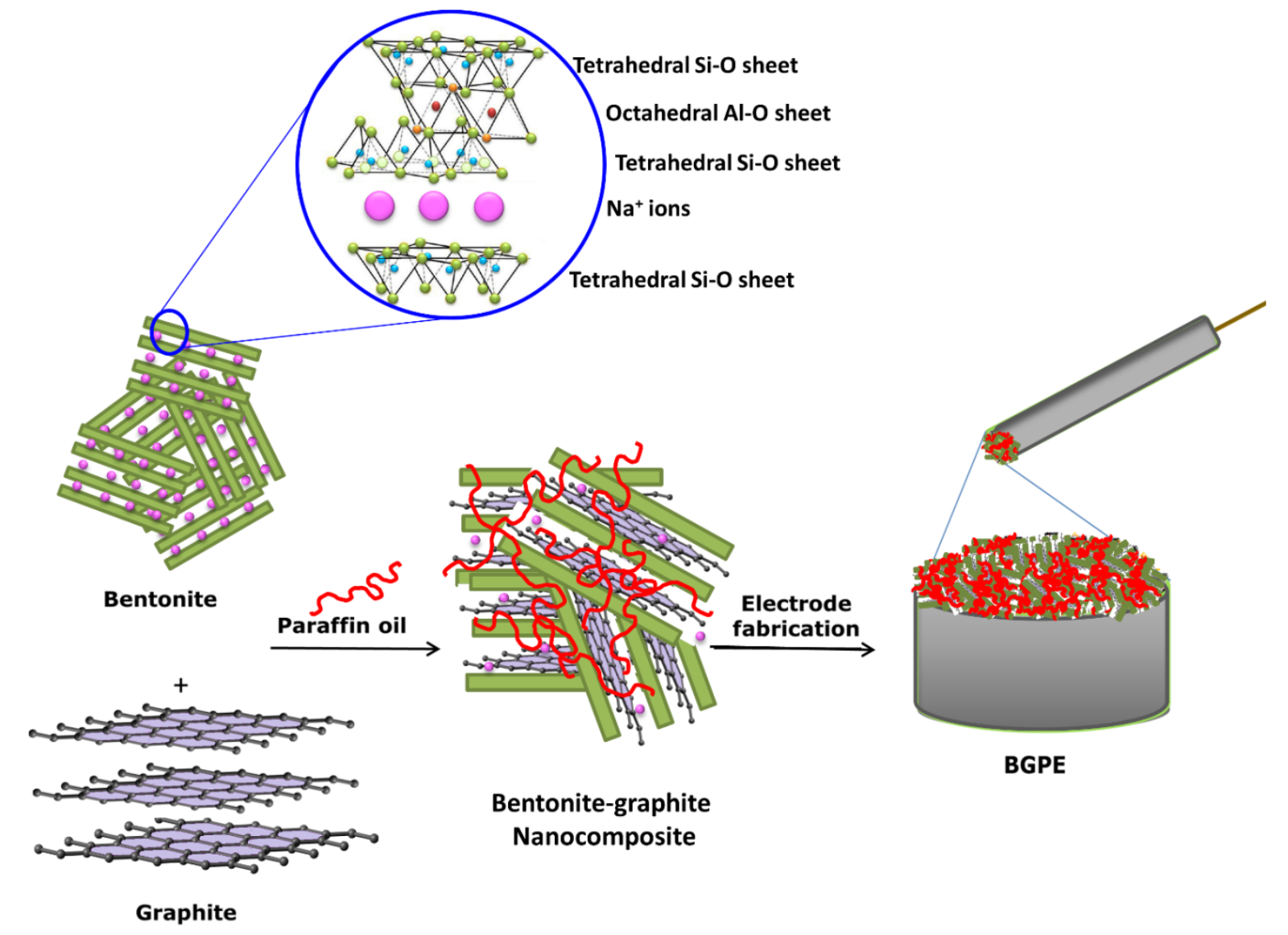

Figure 1: Schematic illustration for the fabrication of BGPE. 


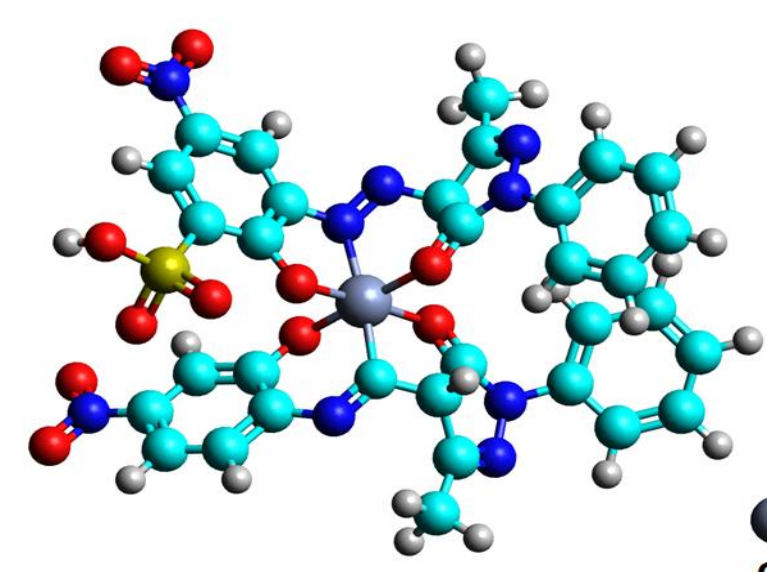

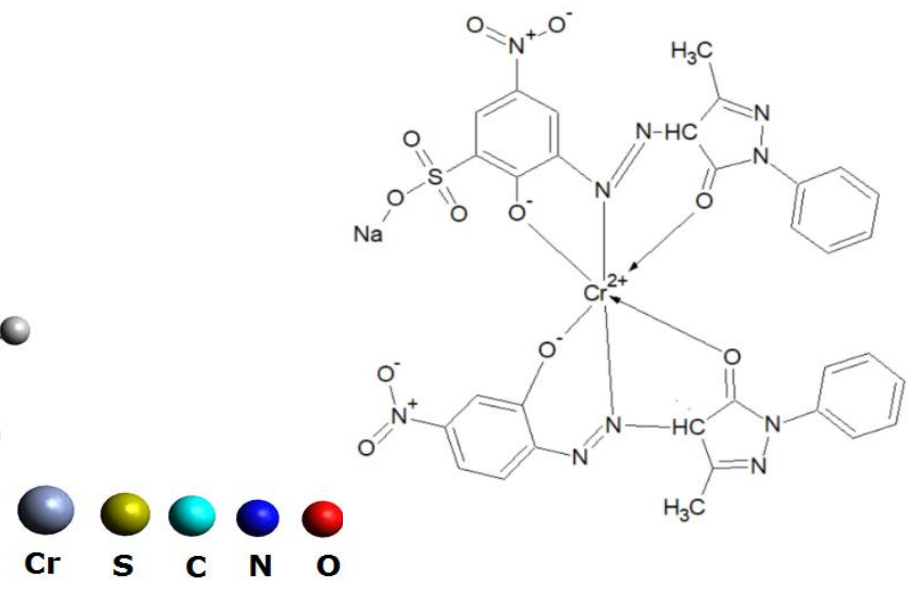

Scheme 1: Molecular structure of Lanaset Red G in 3D (left side) and 2D views (right side).

\section{Diffuse Reflectance Fourier Transform Spectroscopy (DRIFT)}

DRIFT spectroscopy technique is used to characterize the electrode surfaces. The main advantages of this technique are that it provides an easy sample preparation and enables to analyze non-transparent and heterogeneous samples (16). Figure 2 shows the DRIFT spectra obtained from the GPE and BGPE surfaces.

For BGPE sample, the strong band located at $1032 \mathrm{~cm}^{-1}$ is assigned to the Si-O stretching vibration while the peaks observed at 465 and 528 are attributed to the Si-O-Si and Si-O-M ( $M=A l, N a, F e)$ bending vibrations, respectively, indicating characteristic tetrahedral Si-O units in the bentonite structure $(7,17)$. In the case of GPE, C-H rocking vibration modes dominate the spectral region of $500-1400 \mathrm{~cm}^{-1}$, showing two small peaks at about 686 and $551 \mathrm{~cm}^{-1}$. Both spectra show the peaks at nearly $1476 \mathrm{~cm}^{-1}$ arising from the $\mathrm{CH}_{3}$ anti-symmetric and $\mathrm{CH}_{2}$ scissoring vibrations of liquid paraffin which is used as the binder agent in the electrodes (18). The bands at 2879 and $2811 \mathrm{~cm}^{-1}$ are also observed in both spectra indicating $\mathrm{C}-\mathrm{H} \mathrm{sp} \mathrm{s}^{2}$ and $\mathrm{C}-\mathrm{H}$ $\mathrm{sp}^{3}$ stretching vibrations. It is well known that the region between $3200-3800 \mathrm{~cm}^{-1}$ belongs to the $-\mathrm{OH}$ stretching vibration bands (19). In the case of BGPE, a broad and prominent peak is appeared at about $3584 \mathrm{~cm}^{-1}$ followed by the small peak at $3718 \mathrm{~cm}^{-1}$ confirming the molecular water units in the bentonite structure. It is not observed a prominent $-\mathrm{OH}$ bands in this region for GPE when compared to the bentonite-containing analog. Thus, it can be clearly said that the incorporation of bentonite to the GPE provides a hydrophilic character to the electrode surface, which is desirable for studying with an aqueous environment in terms of analyzing electrode/electrolyte interfaces. 


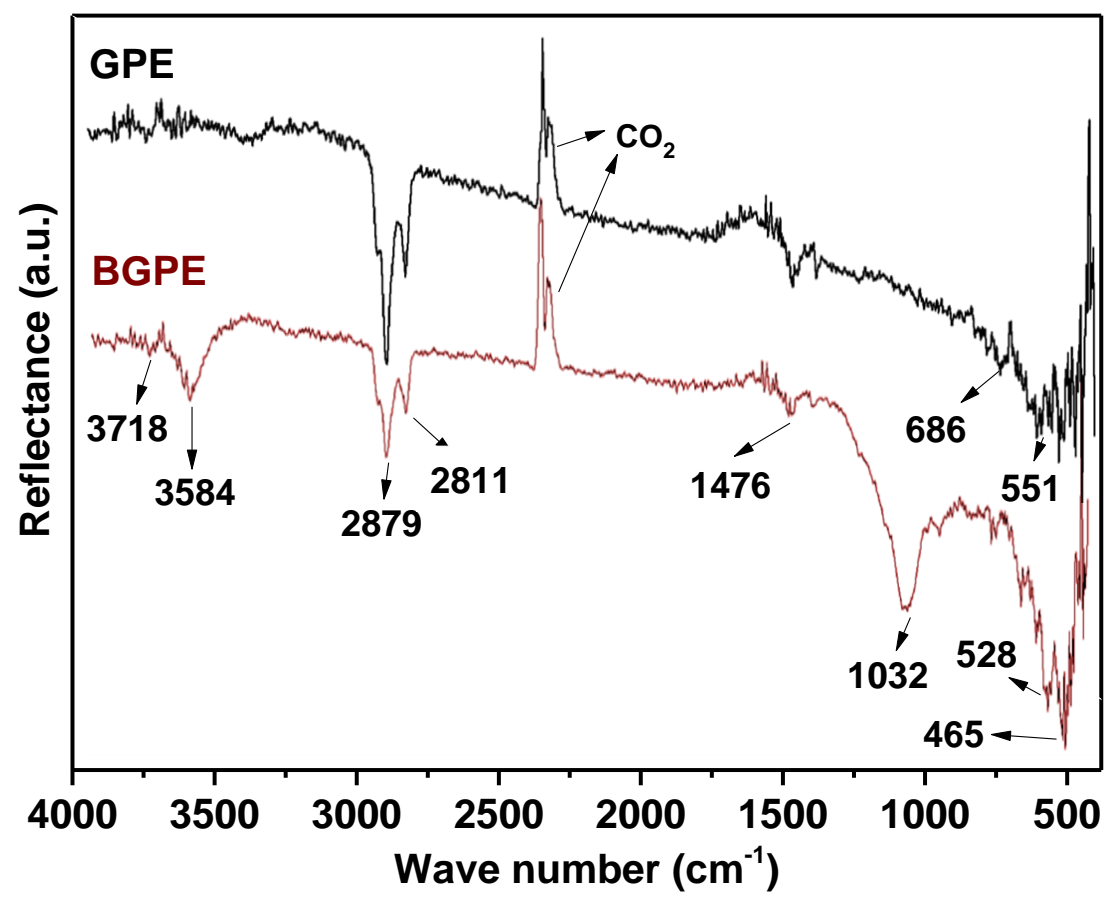

Figure 2: Diffuse reflectance infrared Fourier transform (DRIFT) spectra of GPE and BGPE electrodes. Both spectra are recorded by averaging 100 scans at a resolution of $4 \mathrm{~cm}^{-1}$ using $\mathrm{KBr}(2 \% \mathrm{w} / \mathrm{w})$ as the dispersive medium.

\section{Atomic Force Microscopy (AFM)}

Atomic force microscopy is a cutting-edge technique to generate high-resolution topographic images of surfaces in nanoscale dimensions. It enables to characterize the phase separation depending on unique features of the sample such as softness, elasticity, plasticity, deformability, adhesion, friction etc. (20). Height distributions, flatness, and asymmetry of the active electrode surfaces can also be investigated using this technique to better understand the surface texture. In particular, root mean square ( $\left.R_{R M S}\right)$, skewness ( $\left.S_{s k}\right)$ and kurtosis ( $S_{k u}$ ) parameters provide significant information about the surface asymmetry and flatness, respectively. Positive values of $S_{s k}$ indicate more peaks than valleys while negative results describe more planar surfaces (21). Sku parameters are generally used to obtain information about the surface sharpness. It is well known that there is a strong correlation between $S_{k u}$ parameter and the peakedness of the surfaces and this parameter indicates the tail extremity of the surface distribution. When $S_{k u}$ parameter is smaller than 3 , it is generally expressed that the surface has flatter distribution than normal $(10,20,22)$.

Equations 1 and 2 show the formulation of $S_{s k}$ and $S_{k u}$ coefficients, respectively $(21,23)$.

$$
S_{s k}=\frac{\frac{1}{n} \sum_{i=1}^{n}\left(x_{i}-\bar{x}\right)^{3}}{\left[\frac{1}{n} \sum_{i=1}^{n}\left(x_{i}-\bar{x}\right)^{2}\right]^{3 / 2}}
$$




$$
S_{k u}=\frac{\frac{1}{n} \sum_{i=1}^{n}\left(x_{i}-\bar{x}\right)^{4}}{\left[\frac{1}{n} \sum_{i=1}^{n}\left(x_{i}-\bar{x}\right)^{2}\right]^{2}}
$$

where $x_{i}$ is the $\mathrm{i}^{\text {th }}$ raw data, $\bar{x}$ is the mean value, $n$ and $m$ are the lines and columns in a given matrix of the surface. RRMS parameter is expressed by following equation for 3D surface profiles:

$$
R_{R M S}=\left[\frac{1}{n m} \sum_{i=1}^{n} \sum_{i=1}^{m}\left(x_{i}-\bar{x}\right)^{2}\right]^{1 / 2}
$$

The ten-point height parameter is another surface parameter which is expressed by the difference between the average height of five highest peaks and the average height of the five deepest valleys in the studied area (21).

AFM 3D images, cross-section height profiles, histograms, and phase images of the GPE and BGPE are given in Figure 3. Some of roughness parameters of the electrode surfaces are compared in Table 3. As shown in the table, the average roughness ( $\left.R_{a}\right)$ and the root mean square (RRMS) roughness of GPE are calculated as 64.2 and $76.7 \mathrm{~nm}$, respectively. These values increase to 140 and $180 \mathrm{~nm}$ for BGPE. From these results, it can be concluded that the surface of BGPE has more asymmetrical height distribution than that of GPE surface with respect to their mean surface areas. From $S_{k u}$ parameters, it is observed that the spiky peak distribution dominates the BGPE surface when compared to those of its unmodified counterpart. All these formations on the surfaces are clearly observed from 3D images, cross section profiles and histogram curves in Figure 4. The roughness parameters such as ten point height and peak to peak values in Table 3 also confirm that BGPE has more porous and spiky texture than that of GPE surface. The observed difference between two electrode surfaces is attributed to the presence of bentonite nanoparticles in BGPE. High surface roughness values indicate the higher active surface area which facilitates the electron transfer efficiency between electrode/electrolyte interfaces $(10,22,24)$ which is desirable features for good electrochemical performances.

Table 3: Comparison of roughness parameters of GPE and BGPE.

\begin{tabular}{lll}
\hline & GPE & BGPE \\
\hline Average $(\mathrm{Ra})(\mathrm{nm})$ & 64.2 & 140 \\
Root mean square $\left(\mathrm{R}_{\mathrm{RMS}}\right)(\mathrm{nm})$ & 76.7 & 180 \\
Skewness $\left(\mathrm{S}_{\mathrm{sk}}\right)$ & 0.031 & 0.402 \\
Kurtosis $\left(\mathrm{S}_{\mathrm{ku}}\right)$ & 2.25 & 3.220 \\
Peak-to-peak $(\mathrm{nm})$ & 405.7 & 1300 \\
Ten-point height $(\mathrm{nm})$ & 384.6 & 1260 \\
\hline
\end{tabular}

Figure $4 \mathrm{~g}$ and $4 \mathrm{~h}$ show phase images of the GPE and BGPE, respectively, which are recorded simultaneously with height imaging. As seen in Figure 3d, the GPE surface gives mainly darker domains which are consist of graphite phases. Small particles observed on the surface can be assigned to paraffin oil used as binding agent in the electrode. 
For the BGPE, a strong contrast is observed between dark and light regions associated with different chemical components. The high contrast is caused by larger changes in z-piezo position depending on the physical properties of the surface. It is well known that hard materials are characterized with bright areas due to the increase in tip/surface interactions (25). In this study, lower phase angles are attributed to the graphite and paraffin mixture while the high angles are linked to the bentonite samples in the composite. The histogram plots of phase images based on studied surface show approximately the mean phase angles of $102^{\circ}$ and $175^{\circ}$ for GPE and BGPE, respectively.

\section{Electrochemical Studies}

Cyclic Voltammetry (CV)

Figure 3 shows the representative CV curves of $0.1 \mathrm{mM}$ LRG, which is prepared in $50 \mathrm{mM}$ ABS electrolyte, on the GPE and BGPE. It is clearly seen that the BGPE provides enhanced electrochemical cyclic performance (about 6.7 times higher) as compared to that of the bare GPE. Irreversible two oxidation peaks are observed at about 0.9 and $1.1 \mathrm{~V}$ in the anodic scan direction while in the case of the reverse scan there is no reduction peak is observed for GPE.

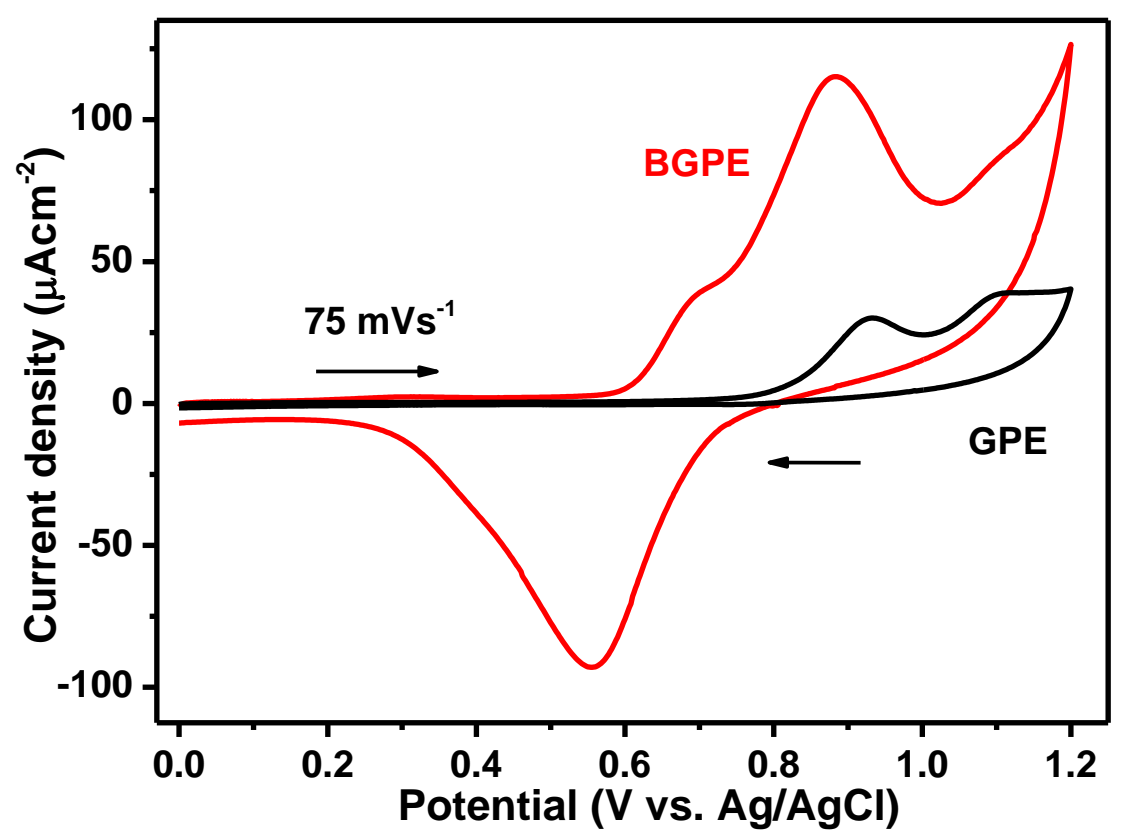

Figure 3: Representative cyclic voltammograms of $0.1 \mathrm{mM}$ LRG solution using GPE and BGPE electrodes. (Experiments are performed applying the scan rate of $75 \mathrm{mVs}^{-1}$ in pH $5 \mathrm{ABS}$ electrolyte)

Under the same experimental conditions, the BGPE shows a more sensitive and prominent redox couple where the oxidation peak observed at about $0.88 \mathrm{~V}$ and the reduction peak detected at about $0.56 \mathrm{~V}$ vs. $\mathrm{Ag} / \mathrm{AgCl}$ reference electrode. The increase in the oxidative peak current observed on BGPE is attributed to the presence of the bentonite which provides a high surface area and suitable electron transfer pathways for the possible redox reactions in LRG which is a kind of 2:1 metal complex azo dye as shown in Scheme 1. 

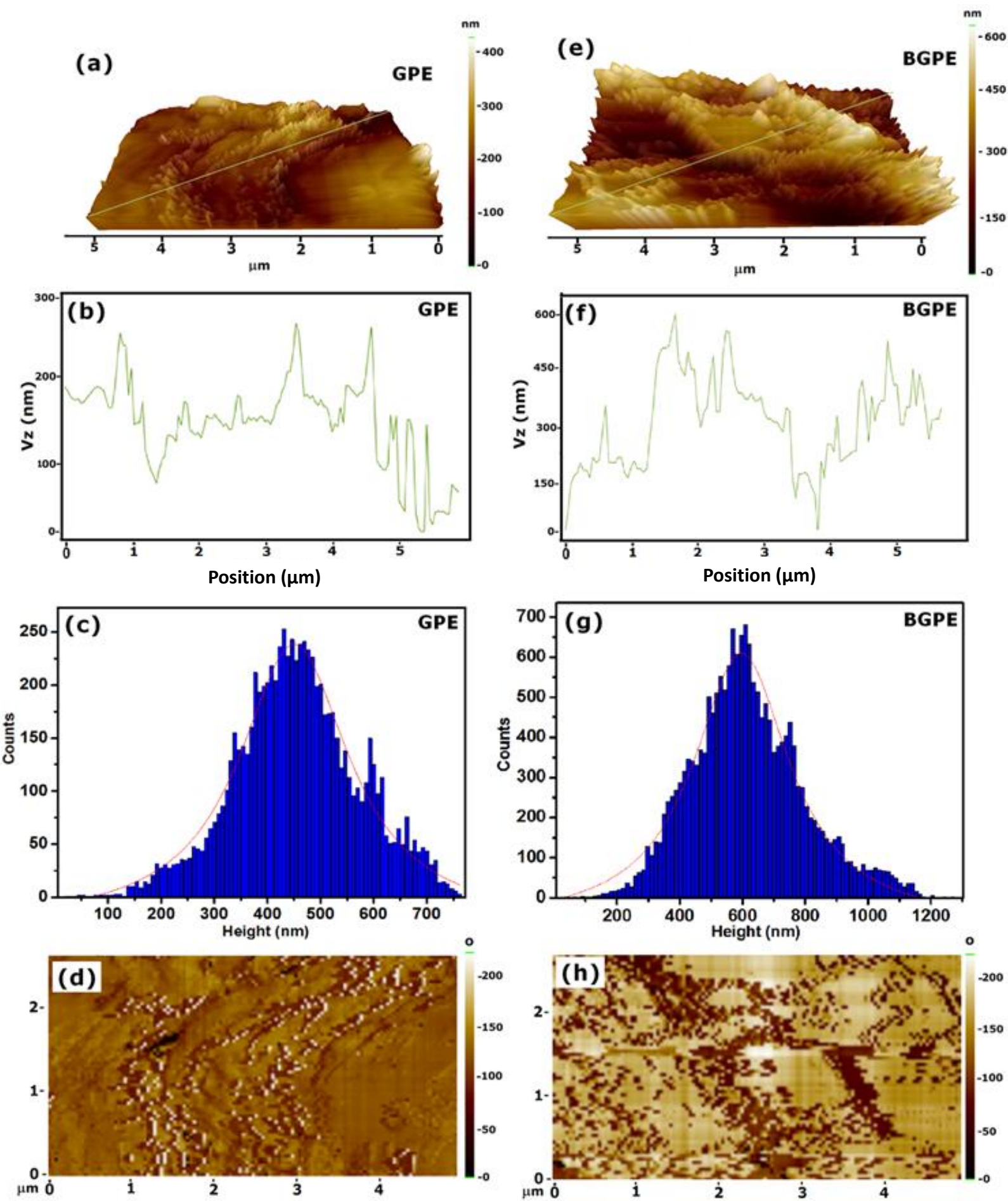

Figure 4: Atomic force microscopy (AFM) images of electroactive GPE and BGPE surfaces. a) 3D surface profile, b) cross-section image along the light green line on Figure $3 a, c)$ histogram of height distributions, d) phase image of the GPE; e) 3D surface profile, f) cross-section image along the light green line on Figure $3 e, g$ ) histogram of height distributions, $h$ ) phase image of the BGPE. Images are obtained using tapping mode under ambient conditions with a cantilever force constant of $\sim 42 \mathrm{~N} / \mathrm{m}$. The $\mathrm{Vz}$ in cross-section diagrams express the voltage applied to the piezo drives responsible for the motion in the $z$ - direction (21).

Effect of scan rates: The effect of the scan rate on peak potentials and current densities of 0.1 $\mathrm{mM}$ LRG at the BGPE is carried out in $\mathrm{pH} 4.75 \mathrm{ABS}$. Various scan rates ranging from $25 \mathrm{mVs}^{-1}$ to $1.0 \mathrm{Vs}^{-1}$ are used to analyze the reaction mechanism occurred at the electrode/electrolyte 
Ortaboy, JOTCSA. 2017; 4(3): 931-952.

RESEARCH ARTICLE

interface of the studied system. Figure 5 shows that there is a monotonic increase in current densities associated with the positive shifts in anodic peak potentials ( $E p_{a}$ ) with increasing scan rates. Considering the size of the diffusion layer, it can be said that the flux to the electroactive surface gets slower with decreasing applied potential. Thus, the magnitude of the current density is closely related to the scan rate (26). The inset of the figure presents CV curves obtained at scan rates up to $75 \mathrm{mVs}^{-1}$. As seen from the figure, initially two prominent oxidation peaks at about 0.69 and $0.87 \mathrm{~V}$ ( $\mathrm{vs}$. $\mathrm{Ag} / \mathrm{AgCl}$ ) and two reduction peaks at $\sim 0.57$ and $\sim 0.42 \mathrm{~V}$ appear for the $\mathrm{CV}$ curve recorded at a scan rate of $25 \mathrm{mVs}^{-1}$. As a function of increasing scan rate, the first oxidation peak weakens further and become a shoulder when applying the scan rate of $75 \mathrm{mVs}^{-1}$. For higher scan rates, single redox couples are detected on the BGPE electrode.

The peak potential separations $\left(E_{p a}-E_{p c}\right)$ between the anodic and cathodic redox couples are calculated as 0.27 and $0.3 \mathrm{~V}$, which are higher than $(0.059 / \mathrm{n}) \mathrm{V}$, indicating quasi-reversible redox reactions occur on the electrode surface. In addition, as shown in Figure 4 , $\left(E_{p a}-E_{p c}\right)$ values for each redox couples tend to increase with increasing scan rates and the square root of scan rate $\left(\mathrm{u}^{1 / 2}\right)$ increases proportionally with increasing current density for both forward and reverse scans (Figure 6). These behaviors further confirm the quasi-reversible characteristics of the electrode reaction, suggesting that both mass transfer phenomena and the kinetics of the electrode reaction take place in the electrode/electrolyte interface. According to the Randles-Sevcik equation, this linear relationship between the peak current and the square root of scan rate for quasi-reversible system is expressed as follows (27):

$$
I_{p}=\left(2.65 \times 10^{5}\right) n^{3 / 2} A C D^{1 / 2} v^{1 / 2}
$$

where $I_{p}$ is the oxidation peak current $(A), A$ is the geometric surface area of the working electrode $\left(\mathrm{cm}^{2}\right), D$ is the diffusion coefficient $\left(\sim 10^{-5} \mathrm{~cm}^{2} \mathrm{~s}^{-1}\right), C$ is the concentration of solution $(\mathrm{mol} \mathrm{L}-1), n$ is the number of electrons transferred in the system, and $v$ is the scan rate $\left(\mathrm{Vs}^{-1}\right)$.

Assuming the diffusion coefficient $(D)$ is $1.10^{-5} \mathrm{~cm}^{2} \mathrm{~s}^{-1}$, the numbers of transferred electrons are determined to be $\sim 4$ and $\sim 3$ for anodic and cathodic reactions, respectively.

To better understand the reaction mechanism, the kinetic behavior of the LRG on BGPE is analyzed using the Laviron plot which is prepared by $\Delta E_{p}$ versus the logarithm of scan rates. $\Delta E_{p}$ is calculated from the formal potential $\left(E_{f}^{0}\right)$ and anodic-cathodic peak potentials. Corresponding parameters shown in Table 4 are used to prepare the Laviron plot which is presented in Figure $5 \mathrm{c}$. The parameters of $v_{a}$ and $v_{c}$ are used to calculate the heterogeneous electron-transfer rate constant $\left(k_{s}\right)$ according to the following equations $(28,29)$ :

$$
\frac{\alpha}{1-\alpha}=\frac{v_{a}}{v_{c}}
$$




$$
k_{S}=\frac{n F \alpha v_{c}}{R T}=\frac{(1-\alpha) n F v_{a}}{R T}
$$

where $\alpha$ and $\mathrm{n}$ are the transfer coefficient and the number of electrons transferred in the reaction, respectively. $F$ is the Faraday constant $\left(96500 \mathrm{Cmol}^{-1}\right), R$ is the ideal gas constant ( $\left.8.314 \mathrm{Jmol}^{-1} \mathrm{~K}^{-1}\right), T$ is the temperature $(\mathrm{K})$. The parameters of $v_{a}$ and $v_{c}$ are determined using the intercepts of straight lines fitted on the Laviron plot and they are shown in Figure $5 \mathrm{c}$. Since quasi-reversible systems tend to exhibit irreversible behavior at very fast scan rates, the Laviron plot is composed of low scan rate values (28). The results show that the transfer coefficient $\alpha$ is 0.51 and the value of $k_{s}$ is $9.2 \times 10-3 \mathrm{~s}^{-1}$.

Table 4: Scan rate $u$, anodic $\left(E_{a}\right)$ and cathodic $\left(E_{c}\right)$ peak potentials, formal potential $\left(E_{f}^{0}\right)$ and $\Delta E$ values for anodic and cathodic branches.

\begin{tabular}{llllccc}
\hline $\mathrm{v}\left(\mathrm{mVs}^{-1}\right)$ & $\log \mathrm{v}$ & $E_{a}(\mathrm{~V})$ & $E_{c}(\mathrm{~V})$ & $\begin{array}{c}E_{f}^{0} \\
\left(E_{a}+E_{c}\right) / 2\end{array}$ & $\begin{array}{c}\Delta E c \\
\left(E_{c}-E_{f}^{0}\right)\end{array}$ & $\begin{array}{c}\Delta E a \\
\left(E_{a}-E_{f}^{0}\right)\end{array}$ \\
\hline 25 & 1.398 & 0.869 & 0.566 & 0.718 & -0.152 & 0.152 \\
50 & 1.699 & 0.886 & 0.556 & 0.721 & -0.165 & 0.165 \\
75 & 1.875 & 0.898 & 0.548 & 0.723 & -0.175 & 0.175 \\
100 & 2.000 & 0.910 & 0.538 & 0.724 & -0.186 & 0.186 \\
200 & 2.301 & 0.948 & 0.518 & 0.733 & -0.215 & 0.215 \\
300 & 2.477 & 0.978 & 0.502 & 0.740 & -0.238 & 0.238 \\
400 & 2.602 & 1.008 & 0.495 & 0.752 & -0.257 & 0.257 \\
500 & 2.699 & 1.032 & 0.478 & 0.755 & -0.277 & 0.277 \\
600 & 2.778 & 1.050 & 0.470 & 0.760 & -0.290 & 0.290 \\
700 & 2.845 & 1.063 & 0.467 & 0.765 & -0.298 & 0.298 \\
800 & 2.903 & 1.079 & 0.464 & 0.772 & -0.308 & 0.308 \\
900 & 2.954 & 1.089 & 0.457 & 0.773 & -0.316 & 0.316 \\
1000 & 3.000 & 1.110 & 0.450 & 0.780 & -0.330 & 0.330 \\
\hline
\end{tabular}




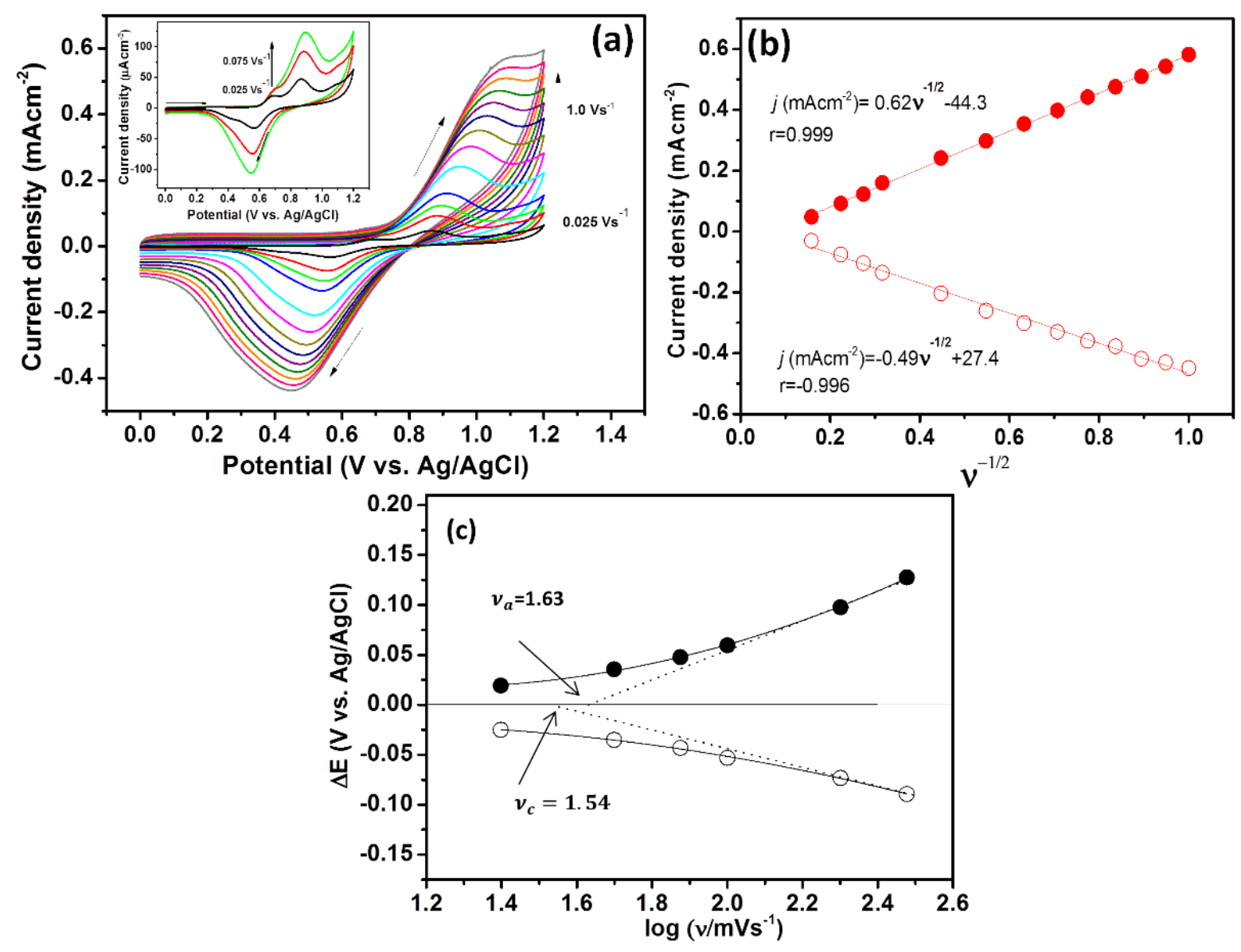

Figure 5: a) CV curves of $0.1 \mathrm{mM}$ LRG on BGPE as a function of scan rates ranging from 25 $\mathrm{mVs}^{-1}$ to $1 \mathrm{Vs}^{-1}$. The inset shows the enlarged view of the first three consecutive cycles, $b$ ) linear relationship between the square root of the scan rate and the current density for the anodic (filled circles) and cathodic (empty circles) peaks, c) Laviron plot ( $E_{p}-E_{f}^{0}$ vs. logarithm of scan rates) of the BGPE in 0.1 mM LRG at $\mathrm{pH} 4.75$.

\section{Effect of $\mathrm{pH}$}

The change observed in peak potentials with the variation of $\mathrm{pH}$ can provide valuable information about proton transfer mechanisms in electrode/electrolyte interfaces (7). Thus, the electrochemical behavior of $0.1 \mathrm{mM}$ LRG is investigated in the $\mathrm{pH}$ range of 2.0 and 6.0 using BGPE to better understand protonation behavior of the studied system. In this regard, the $\mathrm{pH}$ dependence of LRG on BGPE is studied using CV technique as presented in Figure 5a. From this figure, it is revealed that there is a significant change in peak -currents and potentials as a function of $\mathrm{pH}$. Figure $5 \mathrm{~b}$ shows the dependence of peak current densities on the $\mathrm{pH}$. The increasing trend is observed until the $\mathrm{pH}$ reaches 4.75 , above which a significant decrease is observed. In line with this observation, it is obvious that the best performance is obtained in the $\mathrm{pH}$ of 4.75 . Thus, for all electrochemical experiments, this $\mathrm{pH}$ value is used in order to obtain more sensitive results. 

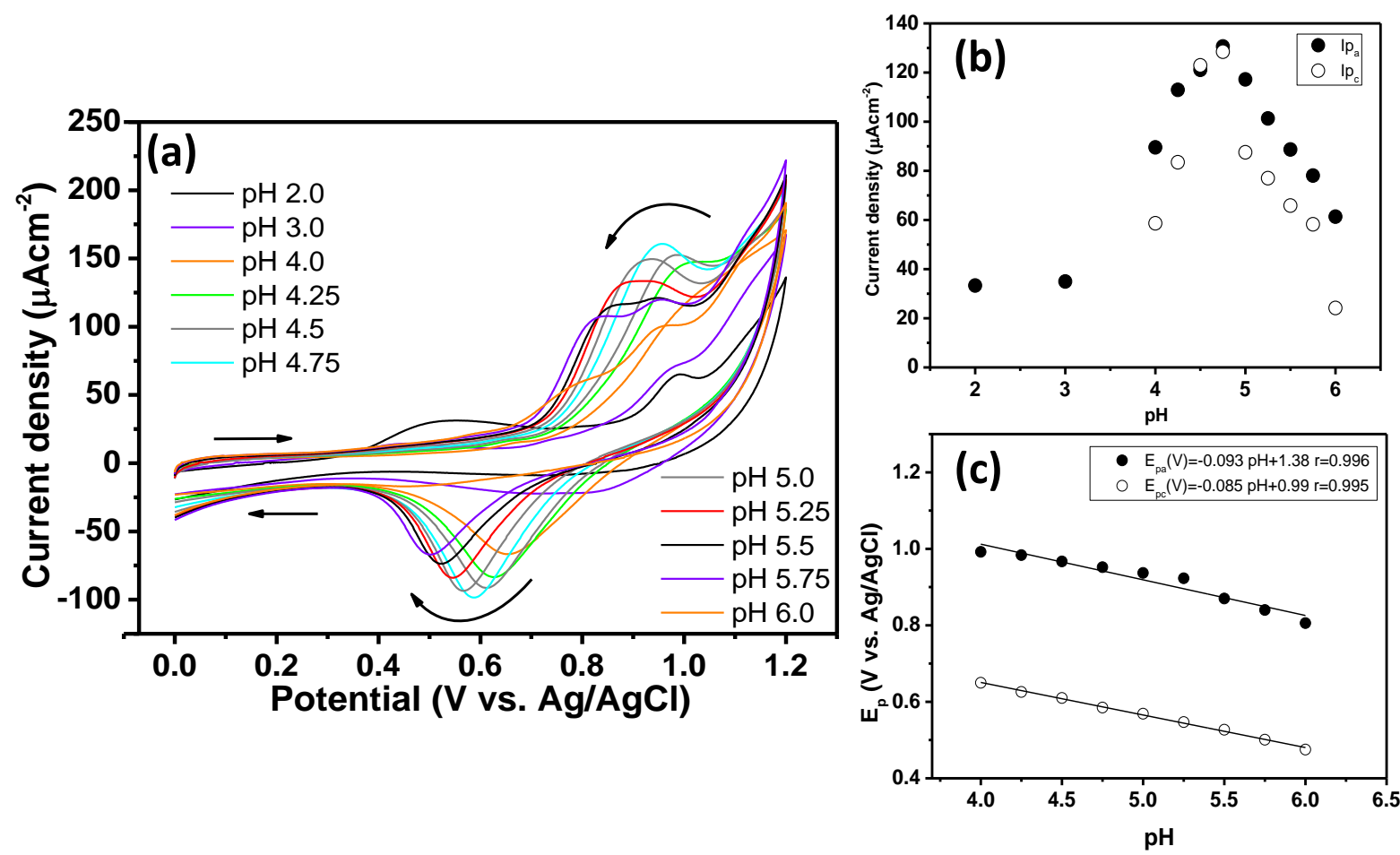

Figure 6: Influence of $\mathrm{pH}$ on a) cyclic performance, b) current densities and c) peak potentials of $0.1 \mathrm{mM}$ LRG for BGPE. The scan rate is $0.1 \mathrm{Vs}^{-1}$, the filled circles show anodic peaks while the empty symbols represent cathodic peaks. Current densities are calculated after the baseline subtraction. The curved arrows observed in Figure 6a show the direction of peak potentials with increasing $\mathrm{pH}$ )

As presented in Figure 5c, a monotonic decrease is observed for potentials of both oxidation (from 0.65 to $0.48 \mathrm{~V}$ ) and reduction peaks (from 0.81 to $0.99 \mathrm{~V}$ ) with increasing $\mathrm{pH}$. The equations of the linear relationship between $E_{p}$ and $p H$ are provided in the figure.

The number of protons involved per molecule, $p$, of the reactant in the rate determining step is determined from the equations of $\mathrm{E}_{\mathrm{p}} \mathrm{vs}$. $\mathrm{pH}$ by the following Nernst equation (10):

$$
\frac{d\left(E_{p}\right)}{d(p H)}=-(0.059 p) / \alpha n
$$

where $\alpha$ is the electron transfer coefficient, $\mathrm{n}$ is the electron transferred in the ratedetermining step and $E_{p}$ is the peak potential as explained earlier.

The results suggest that the number of protons participating in the electrochemical reaction is 3 and 2 for anodic and cathodic scans, respectively.

Taken together, all the results obtained from electrochemical experiments provide an important insight to understand the reaction mechanisms occurred on the electrode surface. Totally, 4 electrons and 3 protons are consumed during the anodic scan while 3 electrons and 2 protons are transferred for the cathodic scan. According to the obtained results, possible reaction mechanisms of the LRG molecule on the BGPE surface are proposed as shown in Figure 7. 
Since the molecular structure of the LRG, which is a kind of $1: 2$ metal:ligand complex, consists of azo $(-N=N-)$ and hydroxyl $(-\mathrm{OH})$ groups, azo-hydrazone tautomeric equilibrium should be taken into account when suggesting possible reaction mechanisms (30). In this regard, the chemical structures, labeled as (I) and (II) in Figure 7, show the azo and hydrazone form of LRG molecule, respectively. The electrochemical experiments revealed that the LRG molecules are oxidized by four-electron/ three-proton transfer on the BGPE surface during the anodic scan. The chemical structure shown as (III) in Figure 7 illustrate the oxidized molecule which is proposed considering the anodic part of CV voltammogram. At a first approximation, the initial process involves a metal-centered oxidation which belongs to the $\mathrm{Cr}$ (II)/ $\mathrm{Cr}$ (IV) oxidation (31). It is proposed that this oxidation process facilitates the cleavage of $\mathrm{Cr}-\mathrm{N}$ bond $(\sim 2.81 \AA)$ due to the higher bond length as compared to those of the $\mathrm{Cr}-\mathrm{O}(\sim 1.95 \AA)$. The resulting molecule is followed by the addition of two molecules of $\mathrm{H}_{2} \mathrm{O}$ and the formation of $-\mathrm{OH}$ groups attached to the azo groups, as shown in molecule (III). Additionally, two-electron withdrawal occurs from both of the $-O$ groups located at the para position of the nitro benzene rings of the ligands. It should also be noted that one of the $-\mathrm{OH}$ groups attached to the pyrazole rings is affected by the oxidation process due to the one proton transfer. The molecular modelling studies, which are obtained by applying universal force field (UFF) and the steepest descent algorithm for geometrical optimization, revealed that the formation of molecule (III) is favorable because in the case of $-\mathrm{OH}$ group attached to the pyrazole ring in the ligand containing sulfonate group (as shown in molecule a), the minimum energy of the molecule is $1982.75 \mathrm{kcalmol}^{-1}$. When the minimum energy calculated considering the $-\mathrm{OH}$ group locates on the pyrazole ring of the other ligand (as shown in molecule b) the total energy is obtained as $1947.27 \mathrm{kcalmol}^{-1}$. These results further confirm that the suggested molecule configuration is favorable in terms of proton elimination from the molecule. The oxidation potential of this step which includes the formation of - $\mathrm{C}-\mathrm{N}$ - group from the $-\mathrm{C}-\mathrm{NH}$ - structure is in well agreement with the observations reported by Acar et al. (7). It is expected that the similar phenomena occur for the reaction pathway over the hydrazone form of the LRG molecule to give the complex (III). 


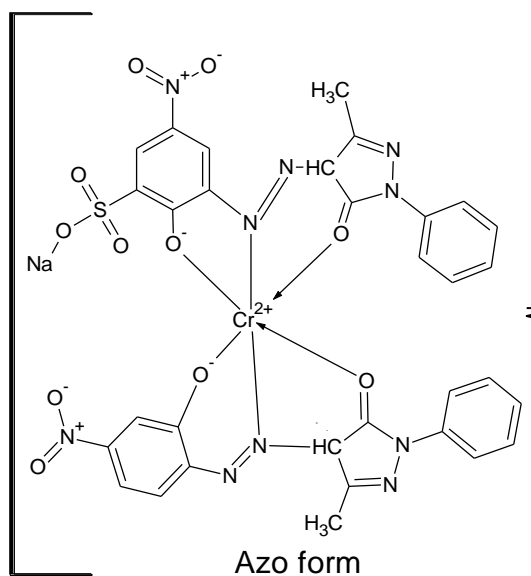

(I)

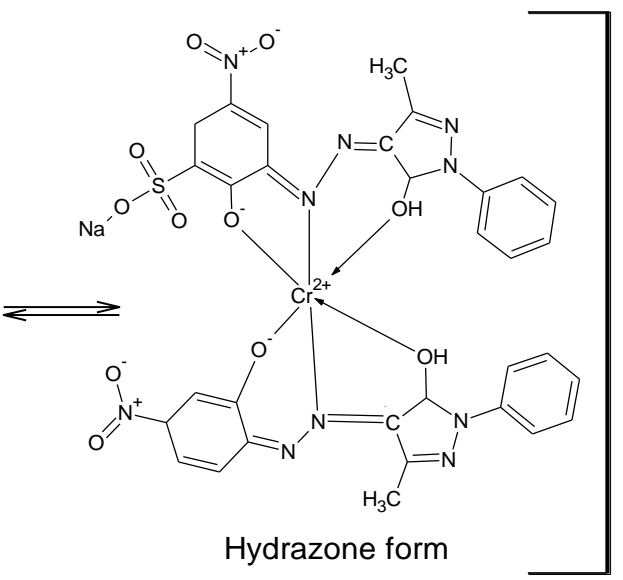

(II)
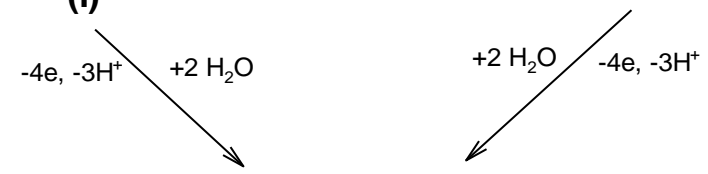

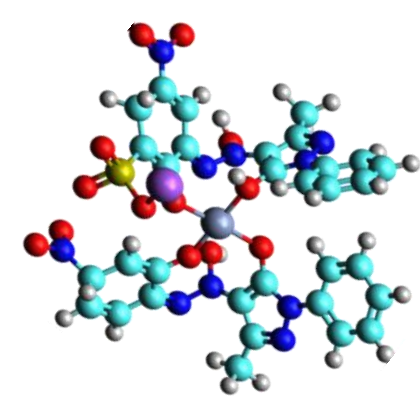

(a)

$1982.75 \mathrm{kcalmol}^{-1}$

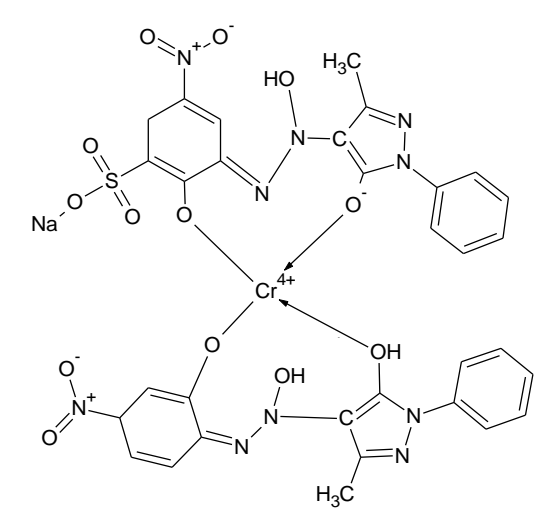

(III)

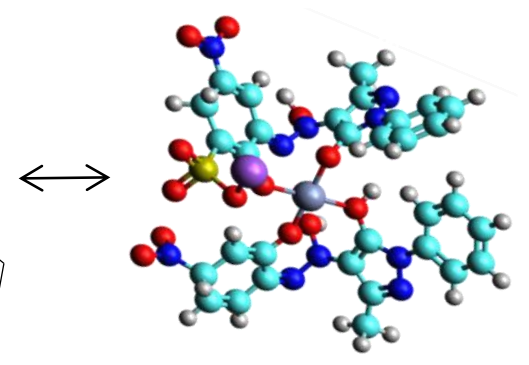

(b)

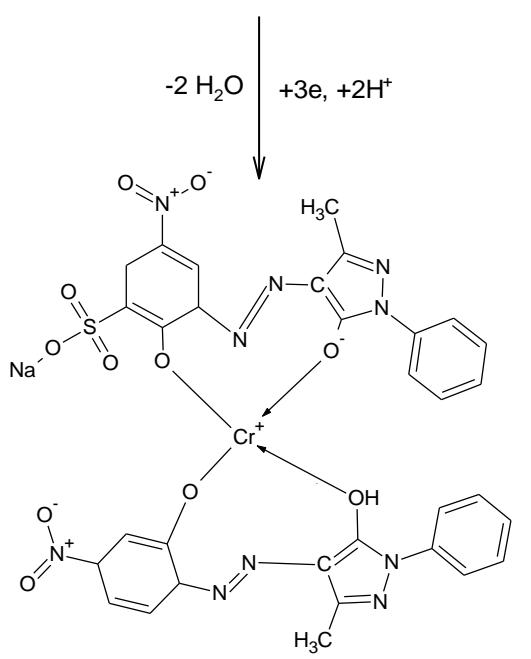

(IV)

Figure 7: Proposed reaction mechanisms for the electrochemical oxidation and reduction of the LRG on BGPE.

Based on the reduction processes, the electrochemical observations indicate that threeelectron/two-proton transfer occurs through the metal- and ligand-centered reductions. In the first step, three electrons are transferred to the center chromium atom and the remaining two protons are accepted by the azo group of the ligand to form - $\mathrm{NH}-\mathrm{NH}$ - group. Simultaneously, 
the elimination of two molecules of $\mathrm{H}_{2} \mathrm{O}$ takes place in the molecule resulting in the removal of hydroxyl groups from - N-N-OH structure for both ligands of the LRG. The reduction of nitro groups may also be suggested for this step but it is well known that the azo groups are reduced prior to the nitro groups in complexes containing both -nitro and -azo groups together (32).

\section{Sensitive determination of LRG dye}

Under optimized experimental conditions, the BGPE is used to detect a trace amount of the LRG dye. SWV technique is performed to estimate the detection limit of LRG using the concentration range of $5.0 \mathrm{nM}-1.6 \mu \mathrm{M}$. Obtained SW voltammograms exhibit increasing trend in both cathodic and anodic peak currents as a function of concentration. Figure 8a shows cathodic peaks and the linear regression plots with corresponding equations (Figure $8 \mathrm{~b}$ ) are calculated from these voltammograms. Three linear segments are obtained for the calibration plot of the peak current density vs. concentration of LRG, as observed in previous studies (7, 33,34 ). The limit of detection ( $L O D=3 \sigma /$ slope) is calculated as $6.5 \pm 0.08 \times 10^{-10} \mathrm{M}$ utilizing the linearity range of $5 \times 10^{-9}-3 \times 10^{-8} \mathrm{M}$ shown in the inset of Figure $8 \mathrm{~b}$. Based on this result, it is revealed that BGPE is a very sensitive electrode for quantitative determination of dyes with azo groups. The high sensitivity of BGPE is attributed to the porous nature of bentonite and excellent conductivity of the graphite on the electrode surface. As compared to the previously reported studies, the present study shows significant improvements in the sensitive determination of azo containing dye using carbon based electrodes $(7,34-39)$.
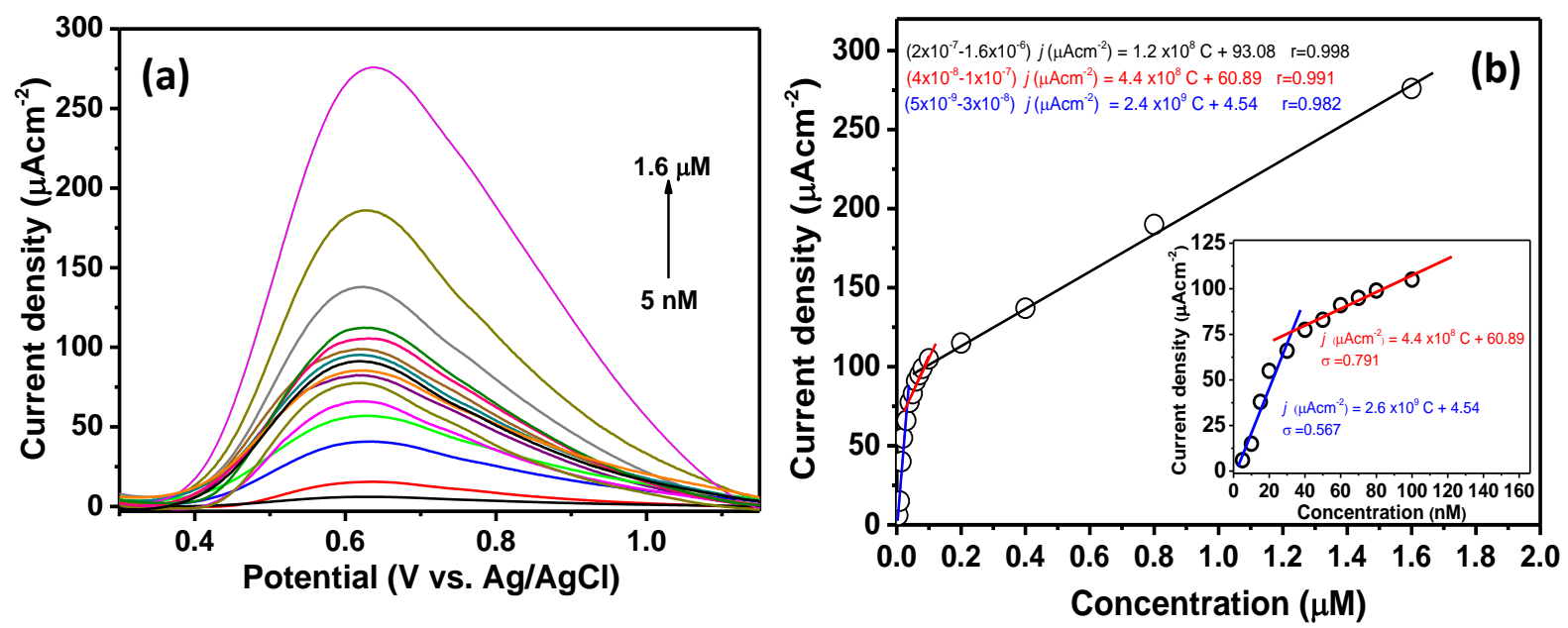

Figure 8: (a) Cathodic square wave voltammograms for different concentrations of LRG on the BGPE in the ABS electrolyte ( $\mathrm{pH} 4.75$, pulse size $100 \mathrm{mV}$, frequency $50 \mathrm{~Hz}$ ), (b) calibration curves prepared from SW voltammograms. (Baseline correction is applied on voltammograms to eliminate the possible baseline signals)

\section{CONCLUSION}

In this study, a graphite paste electrode modified with bentonite (BGPE) is used to evaluate the electrochemical behavior of Lanaset Red G (LRG) which is a kind of the azo group- 
Ortaboy, JOTCSA. 2017; 4(3): 931-952.

RESEARCH ARTICLE

containing acid dye. Cyclic voltammetry experiments revealed that quasi-reversible reactions occur through both metal- and ligand centered transfer processes. The possible reaction mechanisms are estimated taking into consideration of the calculated electron and proton numbers transferred on the electrode/electrolyte interface. Two reaction pathways are proposed considering the possible tautomeric forms of the LRG. The best electrochemical performance is obtained using ABS electrolyte which has a $\mathrm{pH}$ of 4.75 for BGPE. The sensitive determination of LRG is also determined by utilizing SWV technique and results show that the detection limit of LRG is approximately $0.65 \mathrm{nM}$. This low value is associated with the nanoporous nature of the bentonite and good electrical properties of graphite. Taken together, these results suggest that the BGPE is a promising material for easy and sensitive determination of the low concentration of azo containing dyes.

\section{ACKNOWLEDGEMENTS}

The author sincerely thanks to Prof. Gülten Atun from Chemistry Department of Istanbul University for her kind help. The author also acknowledges Samaş Industrial Minerals Inc. and Assoc. Prof. Musa Şahin for their kind donation of Na-bentonite.

\section{REFERENCES}

1. Obasi JNOOIOKO. Environmental and Health Impact of Industrial Wastewater Effluents in Nigeria - A Review. International Journal of Advanced Research in Biological Sciences. 2016;3(6):55-67.

2. Ahmed G, Anawar HM, Takuwa DT, Chibua IT, Singh GS, Sichilongo K. Environmental assessment of fate, transport and persistent behavior of dichlorodiphenyltrichloroethanes and hexachlorocyclohexanes in land and water ecosystems. International Journal of Environmental Science and Technology. $2015 ; 12(8): 2741-56$.

3. Križanec; AMLMB, Valh SVJV. Textile Finishing Industry as an Important Source of Organic Pollutants In: Puzyn T, editor. Organic Pollutants Ten Years After the Stockholm Convention - Environmental and Analytical Update. Rijeka, Crotia: InTech; 2012.

4. Verma AK, Dash RR, Bhunia P. A review on chemical coagulation/flocculation technologies for removal of colour from textile wastewaters. Journal of Environmental Management. 2012;93(1):154-68.

5. Rajasulochana $P$, Preethy $V$. Comparison on efficiency of various techniques in treatment of waste and sewage water - A comprehensive review. Resource-Efficient Technologies. 2016;2(4):175-84.

6. GmbH HTEG. Textile Effects LANASET® dyes Switzerland: Huntsman International LLC 2007 [Available from: https://www.textile-dyes.co.uk/lanaset.pdf.

7. Acar ET, Ortaboy S, Hisarlı G, Atun G. Sensitive determination and electro-oxidative polymerization of azodyes on a carbon paste electrode modified with bentonite. Applied Clay Science. 2015;105-106:13141.

8. Zuo J, Zhang Z, Jiao J, Pang H, Zhang D, Ma H. Sensitive and selective nitrite sensor based on phosphovanadomolybdates H6[PMo9V3040], poly(3,4-ethylenedioxythiophene) and Au nanoparticles. Sensors and Actuators B: Chemical. 2016;236:418-24. 
9. Yu J, Jia J, Ma Z. Comparison of Electrochemical Behavior of Hydroxyl-substituted and Nonhydroxylsubstituted Azo Dyes at a Glassy Carbon Electrode. Journal of the Chinese Chemical Society. 2004;51(6):1319-24.

10. Ortaboy S, Atun G, editors. Electrochemistry of Co(TPTZ)2 Complex on a Carbon Paste Electrode Modified with TiO2 Nanoparticles. Meeting Abstracts; 2016 April 1, 2016.

11. Macht F, Eusterhues K, Pronk GJ, Totsche KU. Specific surface area of clay minerals: Comparison between atomic force microscopy measurements and bulk-gas (N2) and -liquid (EGME) adsorption methods. Applied Clay Science. 2011;53(1):20-6.

12. Mikkelsen PE. Cement-Bentonite Grout Backfill for Borehole Instruments. Geotechnical News. 2002.

13. Sajid M. Bentonite-modified electrochemical sensors: a brief overview of features and applications. Ionics. 2017.

14. Fuenkajorn K, Daemen J]. Sealing of Boreholes and Underground Excavations in Rock: Springer Netherlands; 2012.

15. Inc. SIM. Doğal Bentonit (Katkısız) Turkey: Samaş Industrial Minerals Inc.; 2017 [Available from: http://www.samas.com.tr/tr/urunlerimiz/dogal-bentonit.html.

16. T. Armaroli, T. Becue, Gautier S. Diffuse Reflection Infrared Spectroscopy (DRIFTS): Application to the in situ Analysis of Catalysts. Oil \& Gas Science and Technology - Rev IFP. 2004;59(2):215-37.

17. Motawie AM, Madany MM, El-Dakrory AZ, Osman HM, Ismail EA, Badr MM, et al. Physico-chemical characteristics of nano-organo bentonite prepared using different organo-modifiers. Egyptian Journal of Petroleum. 2014;23(3):331-8.

18. Faheem Khan M, Kim S, Lee D, Schmid S, Boisen A, Thundat T. Nanomechanical identification of liquid reagents in a microfluidic channel. Lab Chip. 2014;14(7):1302-7.

19. Pramanik S, Das G, Karak N. Facile preparation of polyaniline nanofibers modified bentonite nanohybrid for gas sensor application. RSC Advances. 2013;3(14):4574-81.

20. Xu LC, Siedlecki CA. Atomic Force Microscopy. Reference Module in Materials Science and Materials Engineering: Elsevier; 2017.

21. M. Raposo, Q. Ferreira, Ribeiro PA. A Guide for Atomic Force Microscopy Analysis of Soft Condensed Matter. In: A. Mendez-Vilas, Diaz J, editors. Modern Research and Educational Topics in Microscopy. 1: FORMATEX; 2007. p. 758-69.

22. Ortaboy S. Electropolymerization of aniline in phosphonium-based ionic liquids and their application as protective films against corrosion. Journal of Applied Polymer Science. 2016;133(38):n/a-n/a.

23. Bajpai AK, Bhatt R, Katare R. Atomic force microscopy enabled roughness analysis of nanostructured poly (diaminonaphthalene) doped poly (vinyl alcohol) conducting polymer thin films. Micron. 2016;90:127.

24. Hazra P, Jana A, Datta J. Voltammetric deposition of BiCdTe composite films with improved functional properties for photo-electrochemical cells. New Journal of Chemistry. 2016;40(4):3094-103.

25. Crispin X, Jakobsson FLE, Crispin A, Grim PCM, Andersson P, Volodin A, et al. The Origin of the High Conductivity of Poly(3,4-ethylenedioxythiophene)-Poly(styrenesulfonate) (PEDOT-PSS) Plastic Electrodes. Chemistry of Materials. 2006;18(18):4354-60.

26. Fisher AC. Electrochemistry Teaching Notes Department of Chemical Engineering and Biotechnology, \begin{tabular}{l} 
University of Cambridge: University of Cambridge; 2010 [Available from: \\
\hline
\end{tabular} http://www.ceb.cam.ac.uk/research/groups/rg-eme/teaching-notes 
Ortaboy, JOTCSA. 2017; 4(3): 931-952.

27. Brownson DAC, Banks CE. Interpreting Electrochemistry. The Handbook of Graphene Electrochemistry. London: Springer London; 2014. p. 23-77.

28. Pedrosa JRSLCRVA. Polymer brush modified electrode with switchable selectivity triggered by $\mathrm{pH}$ changes enhanced by gold nanoparticles. J Braz Chem Soc. 2014;25(3):453-9.

29. Eckermann AL, Feld DJ, Shaw JA, Meade TJ. Electrochemistry of redox-active self-assembled monolayers. Coordination Chemistry Reviews. 2010;254(15):1769-802.

30. Ball $\mathrm{P}$, Nicholls $\mathrm{CH}$. Azo-hydrazone tautomerism of hydroxyazo compounds-a review. Dyes and Pigments. $1982 ; 3(1): 5-26$.

31. Bose RN, Fonkeng B, Barr-David G, Farrell RP, Judd RJ, Lay PA, et al. Redox Potentials of Chromium(V)/(IV), -(V)/(III), and -(IV)/(III) Complexes with 2-Ethyl-2-hydroxybutanoato(2-/1-) Ligands. Journal of the American Chemical Society. 1996;118(30):7139-44.

32. H. Jayadevappa YS, K. M. Mahadevani B. E. Kumaraswamy, A. K. Sathpathi, B. S. Sherigara. Electrochemical behavior of some industrially important azonaphthol derivatives at glassy carbon electrode. Indian Journal of Chemical Technology. 2006;13:269-74.

33. Gan T, Sun J, Zhu H, Zhu J, Liu D. Synthesis and characterization of graphene and ordered mesoporous $\mathrm{TiO}_{2}$ as electrocatalyst for the determination of azo colorants. Journal of Solid State Electrochemistry. 2013;17(8):2193-201.

34. Ma MM. Voltammetric Determination of Dye-Uptake for C. I. Acid Blue 120 Dyeing Silk. Analytical Letters. 2009;42(18):3073-84.

35. Zhang $Y$, Zhang $X$, Lu X, Yang J, Wu K. Multi-wall carbon nanotube film-based electrochemical sensor for rapid detection of Ponceau 4R and Allura Red. Food Chemistry. 2010;122(3):909-13.

36. Lin $\mathrm{H}$, Li G, Wu K. Electrochemical determination of Sudan I using montmorillonite calcium modified carbon paste electrode. Food Chemistry. 2008;107(1):531-6.

37. Rebane R, Leito I, Yurchenko S, Herodes K. A review of analytical techniques for determination of Sudan I-IV dyes in food matrixes. Journal of Chromatography A. 2010;1217(17):2747-57.

38. Wu Y. Electrocatalysis and sensitive determination of Sudan I at the single-walled carbon nanotubes and iron(III)-porphyrin modified glassy carbon electrodes. Food Chemistry. 2010;121(2):580-4.

39. Mo Z, Zhang Y, Zhao F, Xiao F, Guo G, Zeng B. Sensitive voltammetric determination of Sudan I in food samples by using gemini surfactant-ionic liquid-multiwalled carbon nanotube composite film modified glassy carbon electrodes. Food Chemistry. 2010;121(1):233-7. 
